\title{
Identifying risk-efficient strategies using stochastic frontier analysis and simulation: An application to irrigated cropping in Australia
}

\author{
Brendan Power ${ }^{\mathrm{a}, *}$, Oscar J Cacho ${ }^{\mathrm{b}, 1}$ \\ a Agri-Science Queensland, Queensland Department of Agriculture Fisheries and Forestry, PO Box 102, Toowoomba, QLD 4350, Australia \\ ${ }^{\mathrm{b}}$ UNE Business School, University of New England, Armidale, NSW 2351, Australia
}

\section{A R T I C L E I N F O}

\section{Article history:}

Received 1 July 2013

Received in revised form 7 November 2013

Accepted 26 November 2013

Available online 25 December 2013

\section{Keywords:}

Irrigation

APSIM

Farm bioeconomic model

Risk-efficiency

Stochastic frontier analysis

\begin{abstract}
A B S T R A C T
In irrigated cropping, as with any other industry, profit and risk are inter-dependent. An increase in profit would normally coincide with an increase in risk, and this means that risk can be traded for profit. It is desirable to manage a farm so that it achieves the maximum possible profit for the desired level of risk. This paper identifies risk-efficient cropping strategies that allocate land and water between crop enterprises for a case study of an irrigated farm in Southern Queensland, Australia. This is achieved by applying stochastic frontier analysis to the output of a simulation experiment. The simulation experiment involved changes to the levels of business risk by systematically varying the crop sowing rules in a bioeconomic model of the case study farm. This model utilises the multi-field capability of the process based Agricultural Production System Simulator (APSIM) and is parameterised using data collected from interviews with a collaborating farmer.

We found sowing rules that increased the farm area sown to cotton caused the greatest increase in riskefficiency. Increasing maize area also improved risk-efficiency but to a lesser extent than cotton. Sowing rules that increased the areas sown to wheat reduced the risk-efficiency of the farm business. Sowing rules were identified that had the potential to improve the expected farm profit by ca. $\$ 50,000$ Annually, without significantly increasing risk. The concept of the shadow price of risk is discussed and an expression is derived from the estimated frontier equation that quantifies the trade-off between profit and risk. Crown Copyright $\odot 2013$ Published by Elsevier Ltd. All rights reserved.
\end{abstract}

\section{Introduction}

Bioeconomic simulation models of cropping systems have long been used to allocate farm resources across competing enterprises by comparing management strategies using computer-based experiments (e.g. Cammarano et al., 2012; Farquharson et al., 2008; Gaydon et al., 2011; Meinke et al., 2001; Peake et al., 2008; Power et al., 2011; Rodriguez et al., 2011). Their use is time and cost-efficient compared to the alternative of conducting field experiments that may take years or decades instead of hours or days (Keating and McCown, 2001). Lien et al. (2007) observe that the economic sustainability of a system cannot be measured directly with short-term experiments, but that results can be enhanced through simulation modelling to represent longer timeframes (also see Hansen and Jones, 1996; Pandey and Hardaker, 1995).

Hardaker (2000) observed that the stochasticity of the production environment and the resulting farm business risk were seldom considered in modelling studies. A decade later, the use of

\footnotetext{
* Corresponding author. Tel.: +61 74688 1624; fax: +61 746881193.

E-mail address: brendan.power@daff.qld.gov.au (B. Power).

1 Tel.: +612 6673 3215; fax: +61267733596.
}

stochastic simulation has become more common, but business risk is not always treated appropriately. Climate and price variability mean expected profit on its own is an insufficient criterion to choose between risky alternatives (Behrendt et al., 2006; Carberry et al., 2010; Gaydon et al., 2012; Keating and Carberry, 2010; Lien et al., 2007). If farmers were indifferent to risk the problem would be trivial and strategies could be ranked according to output, profit, partial productivity ratios (e.g. $\$ /$ ha or $\$ / M L$ ), or other measures. However, farmers, as with most people, are risk averse (Hardaker et al., 2004 pp. 4) yet will trade some risk for returns. The amount they trade is dependent on their level of risk aversion.

Most strategies to choose between risky alternatives require the farmer's level of risk aversion to be known a priori (Anderson et al., 1977, pp. 66-69), yet in practice a famer's risk attitude may vary as farm conditions change. For example, if the farm business is in a healthy financial position the farmer may choose strategies expected to yield high returns with relatively high risk, but if the farm business is in financial stress the farmer, or farm creditors, may dictate lower-yield, lower-risk strategies. This example illustrates why it is difficult to elicit a decision maker's utility function (Hardaker, 2000; King and Robison, 1981; Schoemaker, 1982). Fortunately, it is possible to choose between risky alternatives when risk preferences are unknown (Hardaker et al., 2004, pp.140). The 
most common method consists of identifying the set of strategies that achieve the best possible return for any given level of risk (the risk-efficient or mean-variance efficient strategies). Identifying the efficient set allows a decision maker to determine the appropriate strategy for their current level of risk aversion (Antle, 1983; Cacho et al., 1999; Hardaker et al., 2004 p. 143). In the literature the standard deviation or variance of output is often used as a proxy for risk (Anderson et al., 1977; Behrendt et al., 2006; Cacho et al., 1999; Carberry et al., 2010; Gaydon et al., 2012; Parton and Carberry, 1995).

To date, stochastic simulation studies that select optimal strategies in the presence of uncertainty have failed to account for random statistical noise. This means that the possibility of optimal solutions not remaining optimal under different environmental and economic conditions is not considered. In this paper we overcome this limitation by accounting for statistical noise using stochastic frontier analysis when ranking the output of a bioeconomic model. The use of a stochastic frontier is appropriate when a function defining the industry's best performing firms is warranted, as opposed to the average performing firms considered in ordinary least squares (Aigner et al., 1977; Battese and Coelli, 1992, 1995; Meeusen and van den Broeck, 1977). The technique has been extended to quantify the effect of environmental variables on the economic efficiency of the firm (Coelli et al., 1999).

There are many examples in the published literature where stochastic frontier functions have been estimated to compare firms (e.g. Battese and Coelli, 1992, 1995; Coelli et al., 1999; Huang et al., 1986; Kalirajan and Shand, 1989; Nganga et al., 2010; Nonthakot and Villano, 2009; Tran et al., 2008; Villano and Fleming, 2006; Wang et al., 1996; Wilson et al., 2001). Most of them have involved estimation of functions from survey or observational data. None could be found that used bioeconomic model output to produce a dataset for analysis. A common criticism of applying stochastic frontier analysis to compare farms based on survey data is that there are too many differences between farms, farmers and the operational environment to include in the estimated production function. This causes biases in both the estimation of the parameters and the predictors of technical efficiency; therefore comparisons based on estimated technical efficiencies are inappropriate (Coelli et al., 1999, 2005 p. 282; Yotopoulos et al., 1970).
When used to compare management strategies of a particular farm in a modelling framework, as applied here, only differences of interest are varied within the model and hence those biases will not be present.

This study proceeds as follows. Firstly, a bioeconomic model is described and applied to a case study of an irrigated cropping farm enterprise in southern Queensland, Australia. Secondly, the model is used to perform sensitivity analysis on key farm resources and input and output prices. This is conducted to determine if the model behaves sensibly to changes in key variables of the production environment and to rank these variables according their relative effect on farm profit. Lastly, a simulation experiment is designed with the case study farmer and optimal cropping strategies are identified that maximise farm business profit whilst simultaneously minimising farm business risk.

\section{Method}

The modelling framework employed uses a multi-field approach similar to that described in Power et al. (2011). Fig. 1 shows the linkages between the biological and economic model.

\subsection{Biological model}

A whole-farm multi-field variant of APSIM (Keating et al., 2003) was used to model the biological farm system. Management of the simulated farm occurs through a Tool Command Language (TCL) interpreter in APSIM (de Voil et al., 2009). Management strategies include decisions such as which crop to sow or harvest in a particular field and the movement of water between storages to minimise losses due to evaporation and drainage. A complete listing of the TCL code interpreted by APSIM is available in the online Supplementary material.

The choice of crop to sow in each field is achieved by specifying sowing rules that are executed every day for each of the farm fields. When all the sowing rules for a crop evaluate to true, the crop will be sown with specifications for crop variety, fertiliser rates, sowing density and other agronomic factors. Sowing rules allow the farm model to respond to seasonal conditions and

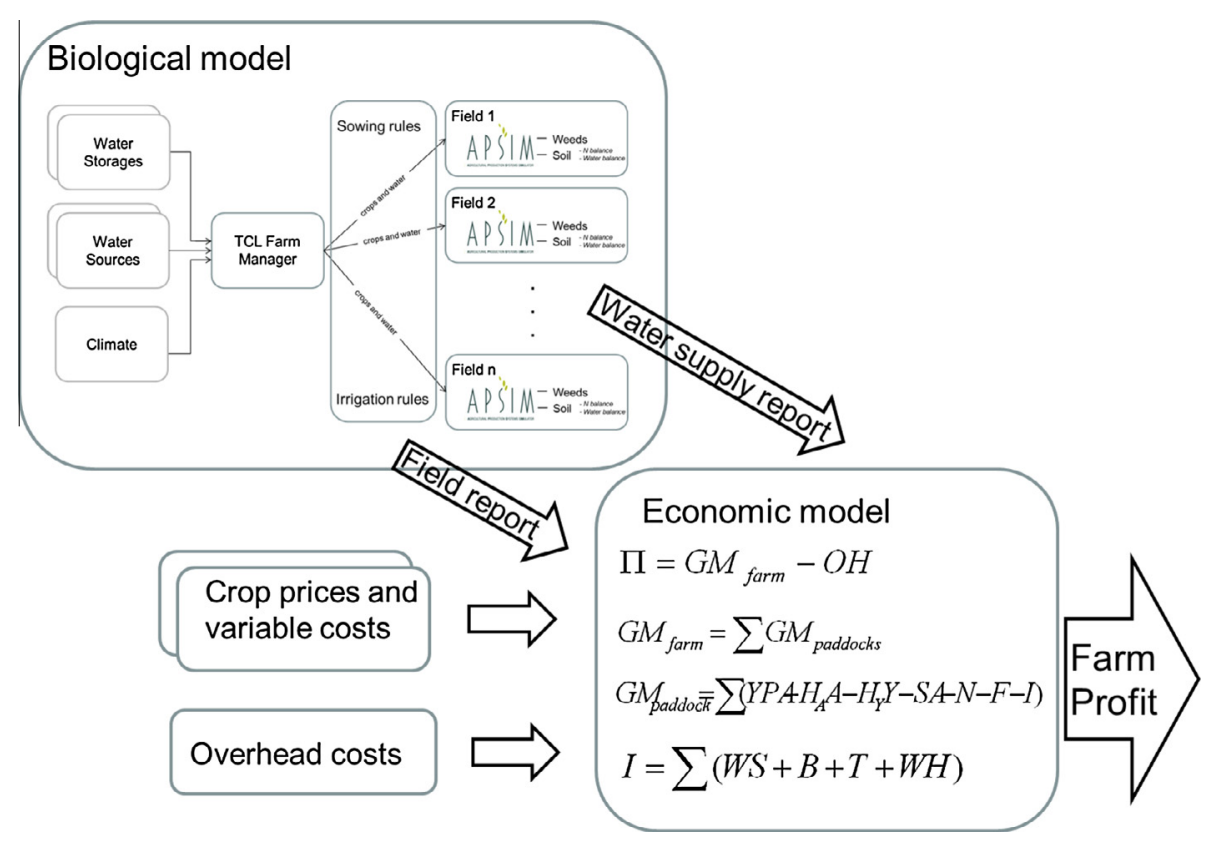

Fig. 1. Schematic of bioeconomic model showing linkages between the biological and economic model. 
production environments, therefore changing the sowing rules can change risk exposure.

Fertiliser rates at sowing are determined by the crop nitrogen requirements less soil nitrogen availability at planting. The daily net balance of soil nitrogen is modelled by APSIM's nitrogen module SOILN (Probert et al., 1997). This means fertiliser amounts and costs vary between seasons and across fields depending on the cropping history of each field. If no crop is able to be planted then the field is left fallow and a simple weed model (de Voil et al., 2009) is used to estimate fallow costs due to weed management.

Within the model the timing and amount of irrigation applied to a crop is determined by the difference between crop demand and soil water supply. When extractable soil water falls below a critical value, water is pumped from a water source, such as a storage or bore, to the field requiring the water. When the level of the storage is sufficiently high, water can gravitate out and pumps are not operated. The level at which this occurs is set for the particular farm based on interviews.

On-farm water sources are modelled via instances of APSIM's WaterSupply module (Gaydon and Lisson, 2005). These can be configured to be: bores with an annual allocation that is renewed annually; sumps that capture on and off farm runoff or river flows; or open storages that have set capacities. The latter supply water when available, are subject to daily water losses due to seepage and evaporation and are "topped-up" from intercepted rainfall, sumps or bores. When daily runoff is greater than some critical value the sump is assumed to be full and water is pumped into the storage, provided sufficient storage capacity is available.

Captured on-farm runoff into farm storages is calculated as.

$R_{M L}=\min \left\{W S_{M L}, T L \sum_{i=1}^{n} \frac{r_{i} A_{i}}{100}\right\}$

where $R_{M L}$ is the total farm runoff (ML) calculated daily; $W S_{M L}$ is the available capacity in ML of the farm water storage of interest; $T L$ is the transmission loss from moving water from the fields into storages and is due to evaporation and drainage in channels; $r_{i}$ is the runoff $(\mathrm{mm})$ from field $\mathrm{i}$ and modelled by APSIM's soil water module SoilWat (Probert et al., 1997); and $A_{i}$ is the area (ha) of field $i$.

Harvested overland flow is modelled using an historical time series of ephemeral flows. To generate a series that correlates with the climate data a multi-year APSIM simulation is calibrated to reproduce the particular farm manager's records. The calibrated model is then used to generate a full historical record of the same length as the historical climate series.

\subsection{Economic model}

The economic model involves assigning a dollar value to every event in the biological model, such as crop sowing and harvest, weed events and operation of farm pumps. This is achieved using the statistical computing environment $\mathrm{R}$ ( $\mathrm{R}$ Development Core Team, 2012). The $R$ code that achieves this appears in the online Supplementary material. Crop prices and variable and overhead costs are obtained through farmer interviews and represent what the farmer expects over the long term. The annual farm profit is given by:

$$
\Pi=\mathrm{GM}_{\text {farm }}-\mathrm{OH}
$$

$G M_{\text {farm }}=\sum G M_{\text {paddocks }}$

$G M_{\text {paddock }}=\sum\left(Y P A-H_{A} A-H_{Y} Y-S A-N-F-I\right)$

$I=\sum(W S+B+T+W H)$ where $\Pi$ is annual farm profit consisting of farm gross margin for the year $\left(G M_{\text {farm }}\right)$ less annual farm overhead costs $(\mathrm{OH})$. Farm gross margin is the aggregate of all fields $\left(G M_{\text {paddock }}\right)$, calculated from revenue for all crops in that field for the year less all costs; $Y$ is the crop yield for cotton (ba/ha) or other crops (t/ha); $P$ is crop price ( $\$ /$ (ba or $\mathrm{t})$ ); $A$ is the crop area grown (ha); $H_{A}$ is the aggregate area-dependent harvest costs $(\$ / \mathrm{ha})$ and $H_{Y}$ is the aggregate yield-dependent harvest costs ( $\$ /($ ba or $\mathrm{t})$ ); $S$ is the aggregate sowing costs $(\$ / \mathrm{ha})$; $N$ is the costs of fertilisers applied to the field $(\$) ; F$ is the fallow cost (the cost of spraying every weed event generated in the weed model in $\$$ ); $I$ is the irrigation costs (\$) for a crop in that field.

The irrigation costs, defined in Eq. (5), are the sum of all pumping costs (\$) from water storages (WS) and bores $(B)$, pumping of return tail water $(T)$ and water harvesting costs $(W H)$. WH is a variable cost calculated for each cropping enterprise by apportioning the pumping costs to harvest the overland flow based on the amount of applied irrigation to each crop for the year.

\subsection{The case study}

The model was applied to a farm in the Darling Downs, located in south-eastern Queensland, Australia. The Darling Downs is approximately $77,400 \mathrm{~km}^{2}$ in size and forms part of the headwaters of the Murray-Darling basin (Fig. 2). This area accounts for over one third of Australia's food production and hence has relatively high agri-political importance. The region's soils are typified by a rich vertisol ideally suited to cropping, which is conducted as both dryland and irrigated. The climate is temperate and sub-humid and although it is characterised by highly variable summer dominant rainfall, moderate falls may occur during any season. This permits an opportunistic cropping system for both summer and winter crops subject to the availability of water. Sources of water for irrigation include diverted rainfall, runoff (i.e. surface water), harvested river flow or pumped ground water.

Irrigated farms in the region have been experiencing increasing pressure due to several factors:

(1) Reductions in long term diversion limits recommended by the draft Murray-Darling basin plan (MDBA, 2010) for both surface water and ground water.

(2) Stress from climate change, with less reliable irrigation water (CSIRO, 2008) and a predicted decline in the value of irrigated production from the Murray-Darling Basin by 2030 of $12 \%$ in a no mitigation scenario (Garnaut, 2011).

(3) Increased risk to ground water systems from coal seam gas mining (DERM, 2010).

(4) Possible trading of water to other uses (National Water Commission, 2009).

(5) Volatile commodity prices, shifting exchange rates and changes in government policies (National Water Commission, 2009).

Each of these issues has the potential to affect the economic viability of farm businesses and will have flow on effects on the wider community.

A number of possible solutions exist to maintain farm output notwithstanding these pressures. These include technological solutions such as conventional plant breeding or genetically modified crops; capital expenditure on farm infrastructure to increase water storage capacity or adopt more efficient irrigation technologies; and improvements in the efficiency of land and water allocation between competing cropping enterprises. Below we analyse the latter option as the simplest, least expensive, and most immediate response to pressures experienced by irrigators.

A typical farm in the region was selected for this study. A number of interviews were conducted with the farmer to elicit the 


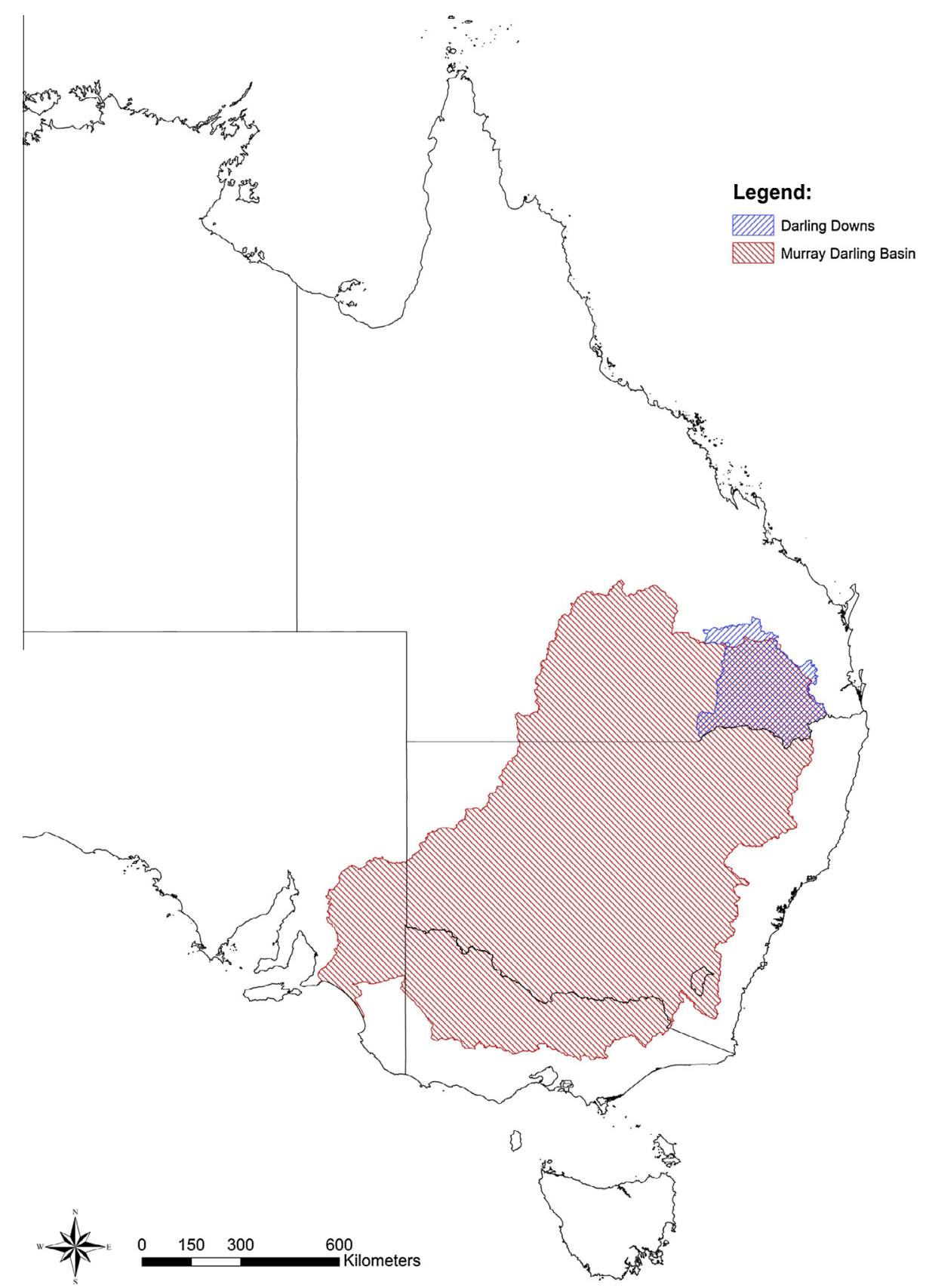

Fig. 2. Map showing location of Darling Downs within the Murray Darling Basin.

required information about the farm and its operations and to validate output from the model. The case study farm is an irrigated grain-cotton enterprise situated on the eastern Darling Downs. The nearest Bureau of Meteorology (BOM) recording station to the farm indicates the area has an average annual rainfall of ca. $660 \mathrm{~mm} /$ year. These data were used in model runs with missing data in-filled using spatial interpolation (Jeffrey et al., 2001).

Details of the fields and farm storages for the case study farm are presented in the Supplementary materials. The timing and choice of crop to sow in each field on the farm is determined by evaluating the rules in Table 1 on a daily basis. These rules were designed through a process of multiple iterations of eliciting the farmer's rules and observing model output with respect to farm cropping mix and intensity. The sowing rule "Available stored water greater than $\times \mathrm{ML} / \mathrm{ha"}$ considers the aggregated water in farm storages, bore allocation and soil water. This rule sets the farm area to be planted to each crop depending on the amount of available water at the time of sowing.

The mechanism used to express sowing rules and their activation in the model offers extreme flexibility. For example, the farmer indicated that if at the end of the wheat sowing window there is insufficient area planted he will plant some area to wheat irrespective of sowing rain. This is implemented in the model by including a second set of wheat sowing rules: if the date is equal to the end of the sowing window and the farm area already planted to wheat is less than 50 ha, then wheat will be sown. Table 2 lists the agronomic parameters for each crop. Detailed prices and variable costs for each cropping enterprise and farm pumping costs were elicited from the farmer and appear in the additional online material. 
Table 1

Crop sowing rules.

\begin{tabular}{ll}
\hline Crop & Sowing rules \\
\hline Maize & Date between September 15 and September 30 \\
& Farm area planted to maize less than 40 ha \\
& Previous crop not maize \\
& Days past since a harvest greater than 14 \\
& Available stored water greater than $3 \mathrm{ML} / \mathrm{ha}$ \\
Cotton & Date between October 1 and November 15 \\
& Previous crop not cotton \\
& Farm area planted to cotton less than 200 ha \\
& Days since a harvest greater than 14 \\
& Available stored water greater than $3 \mathrm{ML} / \mathrm{ha}$ \\
Sorghum & Date between November 16 and November 30 \\
& Rain over 3 days greater than $50 \mathrm{~mm}$ \\
& Soil water profile greater than $50 \%$ \\
& Days since a harvest greater than 14 \\
& Date between June 1 and June 30 \\
Farm area planted to wheat less than 80 ha \\
Rain over 3 days greater than 30 mm \\
Days since a harvest greater than 14 \\
Date equals June 30 \\
Fheat & Farm area planted to wheat less than 50 ha \\
& Days since a harvest greater than 14 \\
\hline
\end{tabular}

\subsection{Sensitivity analysis}

Climate variability was adequately accounted for in the biological model by simulating using 111 years of daily climatic data. However, input and output prices were kept constant in the economic model (Eqs. (2)-(5)). Prices and costs faced by farmers vary, and are often unknown when crucial decisions are made. Accordingly, sensitivity analysis was conducted on crop prices and key input costs (pumping and fertiliser costs). A sensitivity analysis was also conducted on farm resource levels to determine their effect on farm profit and to test that the model behaved sensibly to changes in their values. The total farm area (ha) was varied by adding new fields or removing existing fields. Changes in other variables were made by increasing or decreasing their levels.The steps in the sensitivity analysis are as follows: (1) conduct base simulation using all available climate data (i.e.1900-2011) and calculate farm profit $\Pi_{B}$; (2) for a variable of interest $i$ generate a small percentage change $p$ in its level within the model, re-run and calculate farm profit $\Pi_{i}$; (3) repeat step (2) for a range of values of $p$ and for each variable; (4) use Eq. (6) to calculate a distribution of elasticities for each variable. The elasticity, $E_{i}$ is interpreted as the percentage change in farm profit due to a $1 \%$ change in the level of the given variable:

$E_{i}=\frac{\Pi_{i}-\Pi_{B}}{\left|\Pi_{B}\right|} p^{-1}$

\subsection{Simulation experiments}

Simulations were conducted using the following set of sowing rules developed in collaboration with the case-study farmer:

Table 2

Crop agronomy parameters: Soil N levels at sowing indicate the total amount of soil nitrogen required at sowing; irrigation thresholds are expressed as a fraction of the full soil profile.

\begin{tabular}{llll}
\hline Crop & Variety & Soil N at sowing & Fraction of full profile \\
\hline Cotton & S71BR & 240 & 0.55 \\
Maize & dekalb_xl82 & 220 & 0.40 \\
Sorghum & early & 100 & NA \\
Wheat & hartog & 200 & 0.40 \\
\hline
\end{tabular}

(1) the same crop cannot be planted in the same field for two consecutive seasons (disease break stipulation);

(2) the time since the last harvest must be greater than two weeks;

(3) the farm area planted to any crop cannot be greater than $45 \%$ of the total farm area;

(4) the available stored water (SW), for each hectare of crop to be sown must be greater than a target value.

SW is the aggregate of on farm water storages, remaining bore allocation and plant available soil water. This variable can take on values ranging from 0 to 8 in $1 \mathrm{ML} /$ ha increments for each crop in a fractional factorial design. Table 3 lists a subset of these values. The factorial design is fractional because simulations where sorghum SW values are greater than any other crop where removed. This is because sorghum has a relatively lower water requirement than the other summer crops and hence it is not sensible to evaluate strategies where sorghum requires more water per hectare. The total number of simulations, each representing a strategy, is 2025. Each strategy was evaluated in a simulation using the historical climate record from 1900 to 2011.

SW is a metric of both the intention to sow a crop and the crop's production risk. Low values of SW result in a higher probability of sowing more area with relatively higher production risk due to a greater reliance on highly variable in-crop rainfall. Alternatively, higher values of SW result in the likelihood of sowing relatively less area with a lower production risk because crops are less likely to exhaust available water for irrigation.

\subsection{The stochastic frontier function}

The stochastic frontier production function is given by:

$\ln q_{i}=x_{i}^{\prime} \beta+v_{i}-u_{i}$

where $q_{i}$ is the output of the $i$ 'th firm; $x_{i}$ is a vector of inputs or environmental variables for the $i^{\prime}$ th firm, $\beta$ is the vector of estimated parameters, $v_{i}$ is symmetric random noise which is independently and identically distributed $\mathrm{N}\left(0, \sigma^{2}\right)$ and is assumed to be independent of $u ; u_{i}$ is a non-negative half normal random variable for technical efficiency (i.e. $u_{i} \sim \operatorname{iidN}^{+}\left(0, \sigma^{2}\right)$ ). The $x_{i} \beta$ term

Table 3

Subset of possible values in sowing rules for the minimum required stored water per hectare $(\mathrm{SW})$ in for each crop (ML/ha) and the unique simulation number.

\begin{tabular}{llllc}
\hline Cotton & Maize & Wheat & Sorghum & Simulation/strategy number \\
\hline 0 & 0 & 0 & 0 & 0 \\
1 & 0 & 0 & 0 & 1 \\
2 & 0 & 0 & 0 & 2 \\
3 & 0 & 0 & 0 & 3 \\
2 & 1 & 0 & 0 & 11 \\
3 & 1 & 0 & 0 & 12 \\
4 & 1 & 0 & 0 & 13 \\
5 & 1 & 0 & 0 & 14 \\
6 & 1 & 0 & 0 & 15 \\
7 & 1 & 0 & 0 & 16 \\
8 & 1 & 0 & 0 & 17 \\
8 & 2 & 0 & 0 & 26 \\
$\vdots$ & & & & \\
7 & 7 & 7 & 7 & 2016 \\
8 & 7 & 7 & 7 & 2017 \\
7 & 8 & 7 & 7 & 2018 \\
8 & 8 & 7 & 7 & 2019 \\
7 & 7 & 8 & 7 & 2020 \\
8 & 7 & 8 & 7 & 2021 \\
7 & 8 & 8 & 7 & 2022 \\
8 & 8 & 8 & 7 & 2023 \\
8 & 8 & 8 & 8 & 2024 \\
\hline
\end{tabular}


represents the deterministic component and $v_{i}$ and $u_{i}$ together represent the stochastic component of the model. Coefficients are usually estimated using the method of maximum likelihood.

Frontier functions are typically estimated for the purpose of predicting inefficiencies of firms (Coelli et al., 2005, p. 245). When applied to agriculture studies the firm is typically a farm and output is measured by farm production. However, output can also be represented by farm profit in which case Eq. (6) represents a stochastic profit function (e.g. Huang et al., 1986; Nganga et al., 2010 and Wang et al., 1996). The statistical noise, intended to be captured by the $v_{i}$ term in Eq. (6), can occur for the following reasons: (1) due to the lack of relevant explanatory variables which may be omitted inadvertently or because they are too expensive or impossible to measure; (2) due to measurement error; and (3) due to an inappropriate functional form. However, when applied in a modelling framework as done here, statistical noise due to measurement error is implicit in the model parameters and not present in the $v$ term.

\subsection{Choosing between risky alternatives}

The relationship between a farm's business profit and risk can be viewed as a one-input one-output production process where a farmer may trade risk for profit. If a farm is operated to achieve maximum profit for a particular level of risk exposure it is said to be risk-efficient. Such a farm is operating at or close to the efficiency frontier. A farm operating below the risk-efficiency frontier is inefficient because either more profit could be achieved for similar levels of risk or the same profit could be achieved for less risk. The stochastic risk-efficiency frontier, estimated from results from the simulation experiments, is:

$\log \left(E P_{i}\right)=\beta_{0}+\beta_{1} \log \left(\right.$ Risk $\left._{i}\right)+\beta_{2} \log \left(\text { Risk }_{i}\right)^{2}+V_{i}-U_{i}$

where $E P$ is the expected farm profit (mean annual farm profit); Risk is a mean-corrected proxy for farm business risk; $V_{i}$ is a random error assumed to be normally distributed with a mean of zero and constant variance; and $U_{i}$ is the technical inefficiency estimated as:

$$
\begin{aligned}
U_{i}= & \delta_{0}+\delta_{1}\left(\text { CottonSW }_{i}\right)+\delta_{2}\left(\text { MaizeSW }_{i}\right)+\delta_{3}\left(\text { WheatSW }_{i}\right) \\
& +\delta_{4}\left(\text { SorghumSW }_{i}\right)+W_{i t}
\end{aligned}
$$

where CottonSW, MaizeSW, WheatSW and SorghumSW, are parameters for the stored water (SW) at which the respective crop is planted as explained previously; $W$ is a random variable assumed to be distributed by a truncated normal distribution with zero mean and constant variance; and $\beta$ and $\delta$ coefficients are unknown parameters estimated simultaneously using the method of maximum likelihood via the $\mathrm{R}$ implementation of Frontier Version 4.1 (Coelli, 1996; Coelli and Henningsen, 2012).

Incorporating a nested sub-model for the inefficiency term $U$ (Eq. (9)) enables the cropping strategies to influence the stochastic part of the profit-risk frontier in Eq. (8), which permits the inefficiency to vary with each cropping strategy. $V$ and $W$ capture the combined effects of the stochastic climate, which are unobservable at sowing time.

Although the variance of farm business returns is often used as a proxy for risk (Hardaker et al., 2004) this approach fails to differentiate between distributions of farm profit that are negatively and positively skewed. To overcome that problem we use the standard deviation of the lower tail of the truncated distribution, given by:

$\operatorname{Risk}_{i}=S D\left(P_{t i} \mid P_{t i}<\mu_{i}\right)$

where $P_{t i}$ is the annual profit for year $t$ and strategy $i$ and $\mu_{i}$ is the mean of annual farm profits for strategy $i$. This metric for farm business risk better captures risk by considering only the lower tail of the distribution.

Hypothesis tests were conducted to determine if all strategies are fully risk-efficient and to find the crop sowing rules that have an effect on risk-efficiency. The strategies were then ranked according to their risk-efficiency (RE):

$R E_{i}=e^{-U_{i}}$

Typically, when estimating stochastic frontiers the effect of management on efficiency is not directly observable, and its effects are estimated by proxies such as education or age of the decision maker. In this study the effects of management are quantified through the effects of crops' sowing rules on risk-efficiency.

Risk-efficient cropping strategies were identified that have approximately equal levels of risk to the farmer's current management but higher expected farm profit.

\section{Results and discussion}

The model was run for the time period the farmer has been operating with the current farm infrastructure (i.e. 1999-2012). Fig. 3 shows crops sown in each field ( $x$-axis), timing ( $y$-axis) and simulated yields (ba/ha for cotton and $t /$ ha for other crops). This is the final result after revising the sowing rules until the farmer was satisfied that the sowing rules adequately reproduced his current cropping mix and intensity. Other sensibility tests were

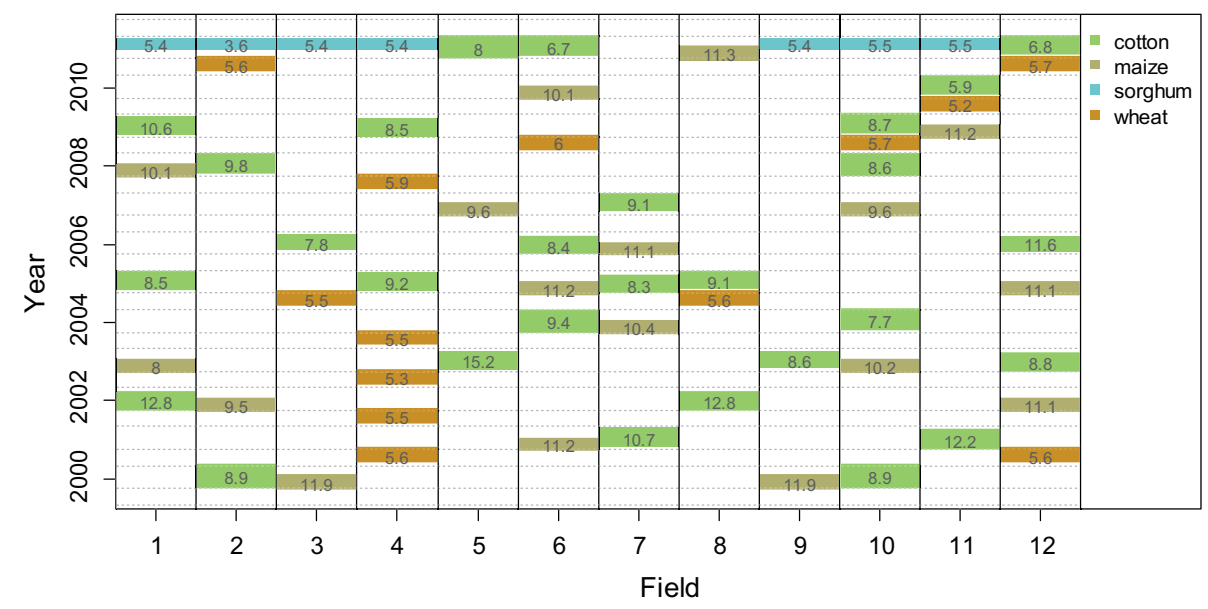

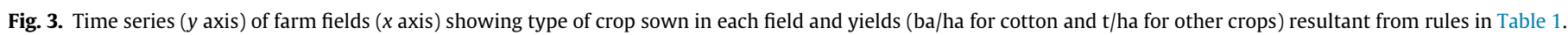




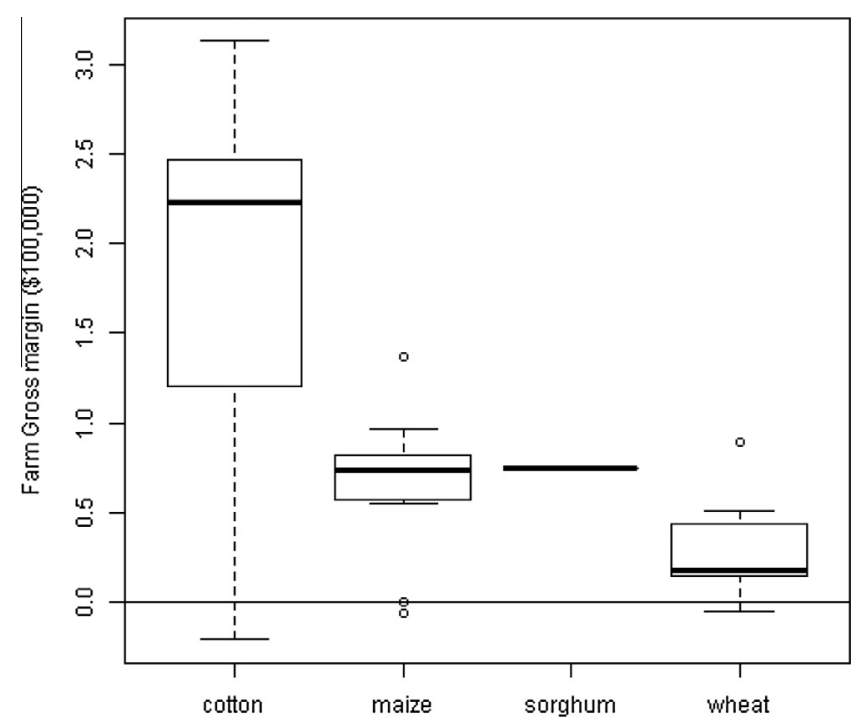

Fig. 4. Annual farm gross margins $(\$ 100,000)$ for each cropping enterprise.

conducted by presenting key output from the biological model to the farmer. The justification for this approach is presented in Holzworth et al., 2011 and is conducted to provide confidence in the performance of the model. The model adequately reproduced the median yields for all crops though with a large variation about the median. The result of this validation process was confidence that the biological model adequately represented the production and water balance of the farm.

\subsection{Economic model output}

Plots of distributions of irrigation, fallow and fertiliser costs were presented to the farmer to validate the economic model. He conceded he was unsure of their true values because he had never accurately measured his costs. Although he stated they were approximately what he would expect.

Fig. 4 shows the range in annual contributions from each cropping enterprise to the total farm gross margin (\$). Cotton is the most important crop in terms of relative farm profit and it is also the riskiest in terms of the greatest probability of a loss. Sorghum has low variability because it is only sown in one season. Fig. 5 shows partial productivity measures for gross margins per farm area sown (\$/ha) and per applied irrigation $(\$ / \mathrm{ML})$. Again cotton is the most profitable crop with respect to farm area sown and applied irrigation, although the relative profitability of maize, when considered per amount of applied irrigation water, approaches that of cotton.

Table 4 presents the sensitivity analysis results. Elasticities of profit with respect to prices of cotton, maize, sorghum and wheat were $4.3,1.3,0.2$ and 0.8 , whereas elasticities for fertiliser and pumping costs were -0.5 and -0.8 . Of the prices considered the cotton price clearly has the largest influence on farm profit.

Regarding changes in farm resources, the annual bore allocation had the greatest effect on farm profit with an elasticity of 0.7 , followed by cropping area and farm storage capacity with elasticities of 0.3 and 0.1 respectively (Table 4). Fig. 6 shows the sensitivity analysis of farm resources graphically. It is interesting that the effects of farm area and storage capacity are similar for increases but they diverge considerably for decreases, with farm area having a greater effect on profit than storage capacity. This suggests that the current size of the farm is approximately optimal for the current water availability. The elasticities for farm resources have high variability as indicated by their standard deviations in Table 4 and Fig. 6. This is due to interactions within the biological model. The standard deviations for the elasticities with respect to prices are zero (Table 4) because prices are linearly related to profits and price changes do not interact with the biological model.

\subsection{Hypothesis tests and parameter estimates}

The maximum likelihood parameter estimates for the stochastic frontier model (8) and the inefficiency effects model (9) are listed in Table 5. A test with null hypothesis $H_{0}: \sigma^{2}=0$ assumes each

Table 4

Farm profit elasticity estimates for farm resources and input and output prices.

\begin{tabular}{lcc}
\hline Variable & Elasticity & \\
\cline { 2 - 3 } & Mean & s.d. \\
\hline Crop prices & 4.3 & \\
Cotton & 1.3 & 0.0 \\
Maize & 0.2 & 0.0 \\
Sorghum & 0.8 & 0.0 \\
Wheat & & 0.0 \\
Costs & -0.5 & \\
Fertiliser & -0.8 & 0.0 \\
Pump operation & & 0.0 \\
Farm resource & 0.3 & \\
Area & 0.7 & 8.0 \\
Bore & 0.1 & 7.8 \\
Storage & & 9.1 \\
\hline
\end{tabular}

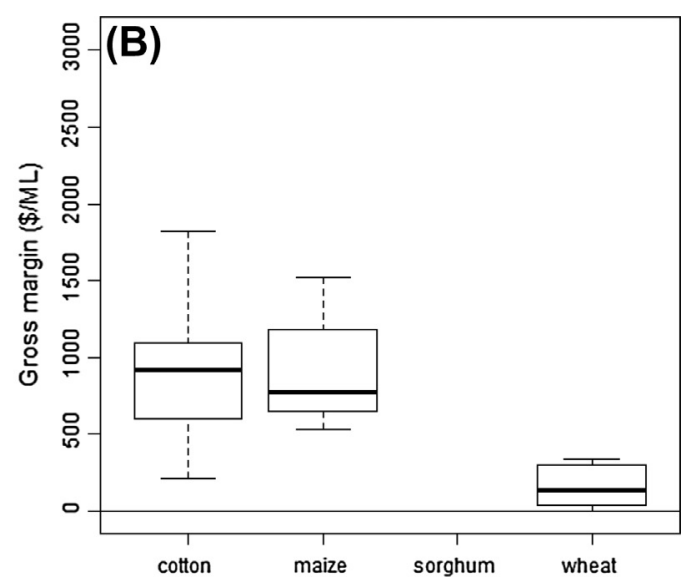

Fig. 5. Distribution for each cropping enterprise of annual gross margins per: (A) area sown (\$/ha) and; (B) applied irrigation (\$/ML). 


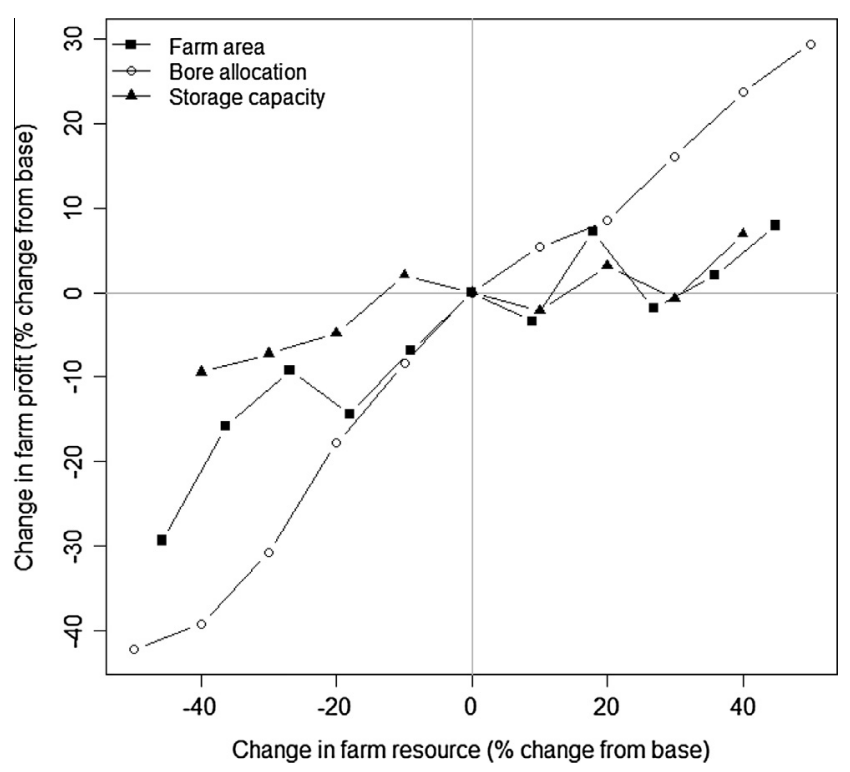

Fig. 6. Percentage change in farm profits against percentage change in levels of farm profits.

strategy is fully risk-efficient. This assumption was found to be highly unlikely with probability rounding to zero and it can be concluded that risk-inefficiencies exist. The variance parameter $\gamma$ indicates $61 \%$ of the total variability in simulated expected farm profit is explained by risk inefficiency. The null hypothesis $H_{0}: \gamma=0$ is a test assuming the inefficiency effects are not stochastic and all variables in the inefficiency effects model $(U)$ have no effect on the level of risk-efficiency. From Table 5 this test is highly significant and hence it is highly likely at least one variable in the inefficiency effects model has a significant effect.

The variable Risk in Eq. (10) was mean-corrected (mean Risk was subtracted from each value) which ensures Risk has a mean of zero and its coefficient estimates are the profit elasticity (Villano and Fleming, 2006). The estimated $\beta$ coefficients for both the first and second order terms for the profit-risk frontier are positive as expected and are significantly different form zero. This indicates the trade-off between profit and risk.

The estimated $\delta$ coefficients for the inefficiency effects model, which are of most interest in this study, are also listed in Table 5. The estimated parameter for the cotton sowing rules, $\delta_{1}$, is positive and significantly different from zero. This is expected, since cotton is the most profitable crop according to a number of metrics ( $\$$ / farm, $\$ /$ ha and $\$ / \mathrm{ML}$ ), and indicates that more stringent water requirements at sowing for cotton increases risk-inefficiency. The result for maize is similar but of lower magnitude. This indicates that even though maize is not the most profitable crop, sowing rules that result in more farm area dedicated to maize improve efficiency but to a lesser extent than a similar increase in cotton area. The estimate for wheat is significant and negative, indicating that as wheat areas increase the risk-efficiency decreases. This is due to the displacement of more profitable crops such as cotton and maize. The estimated coefficient for Sorghum SW, $\delta_{4}$, is not significant ( $p$ value $=0.96$ ) and therefore changes in the area of this crop have no effect on efficiency.

\subsection{Identification of risk-efficient strategies}

Fig. 7 shows the expected farm business profit against Risk for all cropping strategies. Risk-efficient strategies were selected to be those strategies with an RE score in the top decile (i.e. $\mathrm{RE}>0.97$ ). These are identified in Fig. 7 by solid red circles and range in expected annual profit from ca. $\$ 114,000$ to $\$ 243,000$ with a corresponding change in the level of risk. The expected profit and risk of the farmer's current management for the same climate

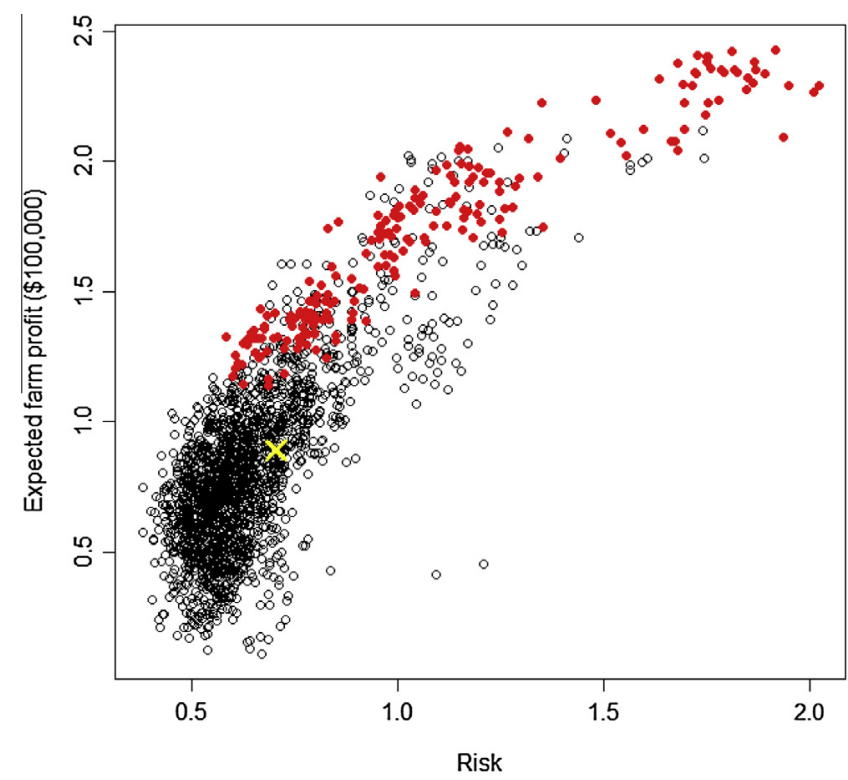

Fig. 7. Expected farm business profit against a proxy for risk (i.e. standard deviation of lower tail of truncated distribution of annual farm profits) for all cropping strategies (black open circles). Each point represents an 111 year simulation from 1900 to 2011. Risk-efficient strategies (solid red circles) and farmer's current management (yellow cross) are identified.

Table 5

Maximum likelihood estimates of parameters for the stochastic profit-risk frontier and inefficiency models (Eqs. (3.1) and (3.2)).

\begin{tabular}{|c|c|c|c|c|c|}
\hline Variable & Parameter & Estimate & Std. error & $z$ Value & $p$ Value \\
\hline \multicolumn{6}{|c|}{ Stochastic frontier } \\
\hline Intercept & $\beta_{0}$ & $1.2 \mathrm{E}+01$ & $1.2 \mathrm{E}-02$ & $2.8 \mathrm{E}+01$ & $<2.2 \mathrm{e}-16$ \\
\hline $\log ($ risk $)$ & $\beta_{1}$ & $6.3 \mathrm{E}-01$ & $2.8 \mathrm{E}-02$ & $2.3 \mathrm{E}+01$ & $<2.2 \mathrm{e}-16$ \\
\hline$(\log (\text { risk }))^{2}$ & $\beta_{2}$ & $1.8 \mathrm{E}-01$ & $3.4 \mathrm{E}-02$ & $5.1 \mathrm{E}+00$ & $2.96 \mathrm{E}-07$ \\
\hline \multicolumn{6}{|c|}{ Inefficiency model } \\
\hline Intercept & $\delta_{0}$ & $-9.6 \mathrm{E}-01$ & $5.0 \mathrm{E}-02$ & $-1.9 \mathrm{E}+01$ & $<2.2 \mathrm{e}-16$ \\
\hline CottonSW & $\delta_{1}$ & $1.9 \mathrm{E}-01$ & $5.2 \mathrm{E}-03$ & $3.7 \mathrm{E}+01$ & $<2.2 \mathrm{e}-16$ \\
\hline MaizeSW & $\delta_{2}$ & $1.1 \mathrm{E}-01$ & $3.8 \mathrm{E}-03$ & $3.0 \mathrm{E}+01$ & $<2.2 \mathrm{e}-16$ \\
\hline WheatSW & $\delta_{3}$ & $-6.8 \mathrm{E}-02$ & $4.0 \mathrm{E}-03$ & $-1.7 \mathrm{E}+01$ & $<2.2 \mathrm{e}-16$ \\
\hline SorghumSW & $\delta_{4}$ & $-2.1 \mathrm{E}-04$ & $4.4 \mathrm{E}-03$ & $-4.8 \mathrm{E}-02$ & 0.9621 \\
\hline \multicolumn{6}{|c|}{ Variance parameters } \\
\hline & $\sigma^{2}$ & $3.8 \mathrm{E}-02$ & $1.8 \mathrm{E}-03$ & $2.1 \mathrm{E}+01$ & $<2.2 \mathrm{e}-16$ \\
\hline & $\gamma$ & $6.1 \mathrm{E}-01$ & $3.7 \mathrm{E}-02$ & $1.6 \mathrm{E}+01$ & $<2.2 \mathrm{e}-16$ \\
\hline log likelihood & 807.0945 & & & & \\
\hline
\end{tabular}




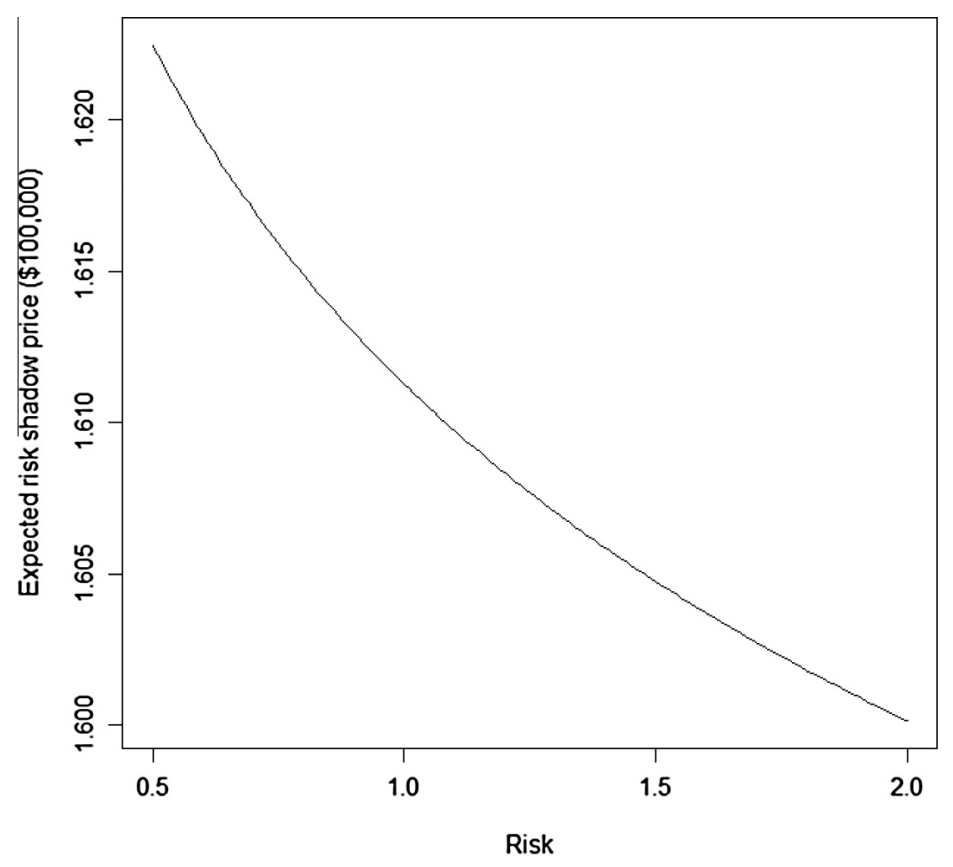

Fig. 8. Simulated expected shadow price of risk versus a proxy for risk (i.e. standard deviation of lower tail of truncated distribution of annual farm profits).

period is identified by the yellow cross in Fig. 7. It is clear the farm is currently being managed below the efficiency frontier and at the lower end of the profit-risk continuum.

Among the risk-efficient strategies, 25 were found to have risk levels approximately equal to that of the farmer's current management. These strategies were presented to the farmer as possible ways he could increase profits by ca. $\$ 50,000$, without having to increase the farm's business risk.

Results display a clear diminishing marginal benefit of risk, as expected based on economic theory. This provides evidence the farm model has adequately captured at least some of the key constraints in the cropping system. Fig. 7 represents a continuum of possible profit and associated risk. Points on the bottom left, with lower return and lower risk, correspond to strategies where relatively less area is sown per ML of available water. Points on the top right area have higher returns and greater risk and correspond to strategies where relatively more area is sown per ML of available farm water. The profit gradient between these extreme responses is ca. $\$ 200,000$ which represents the simulated range of annual farm profit possible from changes to management.

Even though farmers are intrinsically aware that a reward for more risk can be higher business returns, the presentation of the relative position of the farmer's current management can still be informative. It is apparent that the farm is currently operating at the lower end of the profit-risk continuum. By consulting Fig. 7, the farmer could choose a different level of risk and/or profit and change the farm management accordingly. In this way, Fig. 7 can be used as a decision support tool.

The additional benefit to farm business profit from accepting an additional unit of risk is given by the rate at which the expected profit, $E P_{i}$, changes with respect to risk. Setting the riskefficiency score, $U_{i}$, to its mean of 0.75 and $V_{i}$ to 0 and taking the derivative of $E P$ with respect to Risk results, after some manipulation, in:

$$
\frac{\partial E P_{i}}{\partial \operatorname{Risk}_{i}}=\frac{0.36 e^{11.25}+0.63 e^{11.25}}{\operatorname{Risk}_{i}^{0.01}}
$$

This expression represents the shadow price of risk and is presented graphically in Fig. 8. This is the expected change in farm profit due to changes in risk caused by changes in management. It shows the highest returns to risk occur when the farm is operating at relatively low levels of risk exposure.

\section{Concluding comments}

Every season farmers make decisions about how much of the farm area and stored water to allocate to each of a number of cropping enterprises subject to existing constraints of capital and labour. This stored water can be either bound to a parcel of land, as soil water, or unbound water for irrigation that is stored in open water storages. The success, or otherwise, of these decisions is dependent in part on stochastic elements of the growing season that contribute to production risk, such as the timing and amount of precipitation, average and extreme temperatures, and radiation amounts. This paper has demonstrated an analytical framework that helps solve the problem of allocating land and water between cropping enterprises more efficiently. This was accomplished by developing a bioeconomic model of a farm. The model was applied to a case study of an irrigated farm in Australia and used to perform sensitivity analysis on key farm resources and input and output prices. This analysis established that the model behaved sensible to changes in key variables of the production environment and allowed the ranking of these variables according to their relative effect on farm profit. Lastly, the model was used in a simulation experiment where different management strategies were used to quantify the risk-return profile based on the levels of risk exposure associated with each strategy. Cropping strategies were identified that maximise farm business profit for a given level of risk.

The development of a bioeconomic model to estimate a stochastic risk frontier is a novel approach to investigate the effects of management on the trade-offs between farm business profit and risk. When applied in a participatory research approach it can help farmers allocate their land and water between cropping enterprises efficiently by identifying strategies that are on the risk-efficiency frontier. 


\section{Acknowledgements}

The authors acknowledge the valuable contribution made by the Darling Downs farmer who volunteered his time to participate in this study. We also thank: Rene Villano for his suggestion in preparation of this manuscript; Peter de Voil for his help and guidance in writing the TCL code used in the farm model and for making available his existing code; Graham Harris for providing useful comments; and Peter Davis for creating the map in Fig. 1. We also thank the two anonymous reviewers for their valuable comments.

\section{Appendix A. Supplementary data}

Supplementary data associated with this article can be found, in the online version, at http://dx.doi.org/10.1016/j.agsy.2013.11.002.

\section{References}

Aigner, D.J., Lovell, C.A.K., Schmidt, P., 1977. Formulation and estimation of stochastic frontier production function models. J. Appl. Econometr. 6, 21-37.

Anderson, J.R., Dillon, J.L., Hardaker, J.B., 1977. Agricultural Decision Analysis. Iowa State University Press, Ames.

Antle, J.M., 1983. Incorporating risk in production analysis. Am. J. Agr. Econ. 65, 1099-1106.

Battese, G.E., Coelli, T.J., 1992. Frontier production functions, technical efficiency and panel data: with application to paddy farmers in India. J Prod. Anal. 3 (1-2), 153-169.

Battese, G.E., Coelli, T.J., 1995. A model for technical inefficiency effects in a stochastic frontier production function for panel data. Empirical Econ. 20, 325-332.

Behrendt, K., Cacho, O., Scott, J.M., Jones, R., 2006. Methodology for assessing optimal rates of pasture improvement in the high rainfall temperate pasture zone. Aust. J. Exp. Agr. 46, 845-849.

Cammarano, D., Payero, J., Basso, B., Wilkens, P., Grace, P., 2012. Agronomic and economic evaluation of irrigation strategies on cotton lint yield in Australia. Crop Pasture Sci. 63 (7), 647-655.

Cacho, O.J., Bywater, A.C., Dillon, J.L., 1999. Assessment of production risk in grazing models. Agric. Syst. 60 (2), 87-98.

Carberry, P.S., Bruce, S.E., Walcott, J.J., Keating, B.A., 2010. Innovation and productivity in dryland agriculture: a return-risk analysis for Australia. J. Agric. Sci. 149 (S1), 77-89.

Coelli, T.J., 1996. A Guide to FRONTIER Version 4.1: A Computer Program for Stochastic Frontier Production and Cost Function Estimation. CEPA Working Paper 96/08, Department of Econometrics, University of New England, Armidale.

Coelli, T.J., Perelman, S., Romano, E., 1999. Accounting for environmental influences in stochastic frontier models: with application to international airlines. J. Prod. Anal. 11, 251-273.

Coelli, T.J., Henningsen, A., 2012. Frontier: A Package for Stochastic Frontier Analysis (SFA) in R" Retrieved from Frontier.r-forg.r-project.org.

Coelli, T.J., Rao, D.S.P., O'Donnell, C.J., Battese, G.E., 2005. An Introduction to Efficiency and Productivity Analysis. Springer.

CSIRO, 2008. Water Availability in the Murray- Darling Basin. A report from CSIRO to the Australian Government. Collingwood, Victoria, Australia: CSIRO.

Department of Environment and Resource Management (DERM), 2010. Healthy Head Waters Coal Seam Gas Water Feasibility Study, retrieved from <www.derm.qld.gov.au/factsheets/pdf/water/w184.pdf>.

de Voil, P., Rodriguez, D., Power, B. Rossing, W.A.H., 2009. Simulation of whole farm management decisions. In: Anderssen, R.S., Braddock, R.D., Newham, L.T.H. (Eds.), 18th World IMACS Congress and MODSIM09 International Congress on Modelling and Simulation. Modelling and Simulation Society of Australia and New Zealand and International Association for, Mathematics and Computers in Simulation, July 2009, pp. 2377-2383. ISBN:978-0-9758400-7-8. <http:// www.mssanz.org.au/modsim09/B3/deVoil.pdf>.

Farquharson, R.J., Cacho, O.J., Mullen, J.D., Schwenke, G.D., 2008. An economic approach to soil fertility management for wheat production in north-eastern Australia. Agricultural Econ. 38 (2), 181-192.

Garnaut, R., 2011. The Garnaut Review 2011: Australia in the Global Response to Climate Change/Ross Garnaut Cambridge. Cambridge University Press.

Gaydon, D.S., Lisson, S.N., 2005. APSIM WaterSupply. In: Inman-Bamber, G., Attard, S., (Eds.), Inventory of Australian Software tools for Best Use ofWater On-Farm Final Report for Project 3.08, CRC for Irrigation Futures.

Gaydon, D.S., Meinke, H., Rodriguez, D., 2011. The best farm-level irrigation strategy changes seasonally with fluctuating water availability. Agr. Water Manage 103, 33-42.

Gaydon, D.S., Meinke, H., Rodriguez, D., McGrath, D.J., 2012. Comparing water options for irrigation farmers using Modern Portfolio Theory. Agr. Water Manage. 115, 1-9.
Hansen, J.W., Jones, J.W., 1996. A systems framework for characterizing farm sustainability. Agric. Syst. 51 (2), 185-201.

Hardaker, J.B., 2000. Some Issues in Dealing with Risk in Agriculture, Working Paper Series in Agricultural and Resource Economics.

Hardaker, J.B., Huirne, R.B.M., Anderson, J.R., Lien, G., 2004. Coping with Risk in Agriculture, second ed. CABI Publishing, Wallingford.

Holzworth, D.P., Huth, N.I., deVoil, P.G., 2011. Simple software processes and tests improve the reliability and usefulness of a model. Environ. Model. Softw. 26 (4), 510-516.

Huang, C.J., Tang, A.M., Bagi, F.S., 1986. Two views of efficiency in Indian agriculture Can. J. Agr. Econ. 34, 209226.

Jeffrey, S.J., Carter, J.O., Moodie, K.M., Beswick, A.R., 2001. Using spatial interpolation to construct a comprehensive archive of Australian climate data. Environ. Model. Softw. 16 (4), 309-330.

Kalirajan, K.P., Shand, R.T., 1989. A generalized measure of technical efficiency Appl. Econ. 21 (1), 25-34.

Keating, B.A., Carberry, P.S., Hammer, G.L., Probert, M.E., Robertson, M.J., Holzworth, D., Huth, N.I., Hargreaves, J.N.G., Meinke, H., Hochman, Z., McLean, G., Verburg, K., Snow, V., Dimes, J.P., Silburn, M., Wang, E., Brown, S., Bristow, K.L., Asseng, S. Chapman, S., McCown, R.L., Freebairn, D.M., Smith, C.J., 2003. An overview of APSIM, a model designed for farming systems simulation. Eur. J. Agron. 18 (34), 267-288.

Keating, B.A., Carberry, P.S., 2010. Emerging opportunities and challenges for Australian Broadacre agriculture. Crop Pasture Sci. 61, 269-278.

Keating, B.A., McCown, R.L., 2001. Advances in farming systems analyses. Agric Syst. $70(2-3), 555-579$.

King, R.P., Robison, L.J., 1981. An interval approach to measuring decision makers preferences. Am. J. Agr. Econ. 63, 510-520.

Lien, G., Hardaker, J.B., Flaten, O., 2007. Risk and economic sustainability of crop farming systems. Agric. Syst. 94, 541-552.

Meeusen, W., van den Broeck, J., 1977. Efficiency estimation from Cobb-Douglas production functions with composed error. Int. Econ. Rev. 18, 435-444.

Meinke, H., Baethgen, W.E., Carberry, P.S., Donatelli, M., Hammer, G.L., Selvaraju, R. Stocklee, C.O., 2001. Increasing profits and reducing risks in crop production using participatory systems simulation approaches. Agric. Syst. 70 (2-3), $493-$ 513.

Murray-Darling Basin Authority (MDBA), 2010. Guide to the proposed Basin Plan. Murray Darling Basin Authority, Canberra.

National Water Commission, 2009. Australian Water Reform 2009: Second Biennial Assessment of Progress in Implementation of the National Water Initiative. National Water Commission, Canberra.

Nganga, S.K., Kungu, J., Ridder, N.D., Herrero, M., 2010. Profit efficiency among Kenyan smallholders milk producers: a case study of Meru-South district. Kenya. Afr. J. Agric. Res. 5 (4), 332-337.

Nonthakot, P., Villano, R., 2009. Impact of Labour Migration on farm efficiency: a study of maize farming in Northern Thailand. Asia Pac. J. Rural Dev. 14 (2), 1-16.

Pandey, S., Hardaker, J.B., 1995. The role of modelling in the quest for sustainable farming systems. Agric. Syst. 47 (4), 439-450.

Parton, K.A., Carberry, P.S., 1995. Stochastic dominance and mean-standard deviation analysis : some critical issues. Aust. J. Agric. Res. 1995 (46), 1487 1491.

Peake, A.S., Robertson, M.J., Bidstrup, R.J., 2008. Optimising maize plant population and irrigation strategies on the Darling Downs using the APSIM crop simulation model. Anim. Prod. Sci. 48 (3), 313-325.

Power, B., Rodriguez, D., DeVoil, P., Harris, G., Payero, J., 2011. A multi-field bioeconomic model of irrigated grain - cotton farming systems. Field Crop Res. 124 (2), 171-179.

Probert, M.E., Dimes, J.P., Keating, B.A., Dalal, R.C., Strong, W.M., 1997. APSIM's water and nitrogen modules and simulation of the dynamics of water and nitrogen in fallow systems. Agric. Syst. 56, 1-28.

Rodriguez, D., deVoil, P., Power, B., Crimp, S., Meinke, H., 2011. The intrinsic plasticity of farm businesses and their resilience to change. Field Crops Res. 124 157-170.

R Development Core Team (2012). R: A language and environment for statistical computing. R Foundation for Statistical Computing, Vienna, Austria. ISBN 3900051-07-0. <http://www.R-project.org/>.

Schoemaker, P.J.H., 1982. The expected utility model: its variants, purposes evidence and limitations. J. Econ. Lit. 20, 529-563.

Tran, T.B., Grafton, R.Q., Kompas, T., 2008. Firm efficiency in a transitional economy: evidence from Vietnam. Asian Econ. J. 22 (1), 47-66.

Villano, R., Fleming, E., 2006. Technical inefficiency and production risk in rice farming : evidence from central Luzon Philippines. Asian Econ. J. 20 (1), 29-46.

Wang, J., Wailes, E.J., Cramer, G.L., 1996. A shadow-price frontier measurement of profit efficiency in Chinese agriculture. Agr. Econ. 78, 146-156.

Wilson, P., Hadley, D., Asby, C., Unit, R.B., Cb, C., Uk, Y.E.R., 2001. The influence of management characteristics on the technical efficiency of wheat farmers in eastern England. Agr. Econ. 24, 329-338.

Yotopoulos, P.A., Lau, L.J., Kutlu, S., 1970. Labor intensity and relative efficiency in Indian agriculture. Stanford Food Res. Inst. Stud. Agr. Econ. Trade Develop. 9 $43-55$. 